\title{
Index selection of beef cattle for growth and milk production using computer simulation modelling
}

\author{
K. Dzama ${ }^{1 \#}$, J.P. Walter ${ }^{2}$, F. Ruvuna ${ }^{2 *}$, J.O. Sanders ${ }^{2}$ and M. Chimonyo ${ }^{1}$ \\ ${ }^{1}$ Department of Paraclinical Veterinary Studies, University of Zimbabwe, P. O. Box MP167 Mt Pleasant, Harare, \\ Zimbabwe; ${ }^{2}$ Department of Animal Science, Texas A\&M University, College Station 77843, USA
}

\begin{abstract}
The Texas A\&M University (TAMU) Beef Cattle Production model was expanded to include basic concepts of quantitative genetics. The traits simulated were birth weight, yearling weight, mature weight and milk production. The progeny inherited attributes from both the sire and the dam. The incorporation of genetic concepts into the model allowed for the introduction of variation between individuals and generations. This was achieved by interfacing the original model with stochastic genetic subroutines including a restricted selection index for desired genetic change. The index included birth weight and yearling weight. In addition, a function for estimating dystocia was also added. The model was used to simulate selection strategies for a small-to-moderate size breed of cattle and a large-size breed using a restricted selection index.

There was an increase in both birth and yearling weight after 20 years of selection in the small-tomoderate size breed, and there was also an increase in dystocia. Antagonistic selection to decrease birth weight and increase yearling weight was simulated for the large breed. Birth weight and dystocia problems declined while yearling weight increased for all classes of animals. In both experiments correlated responses were recorded for mature size and milk production. It was concluded that the modified TAMU Beef Cattle Production model offers breeders an opportunity to compare different selection strategies and evaluate different breeding plans.
\end{abstract}

Key words: beef cattle, simulation model, selection index, genetics, animal breeding

\#Author to whom correspondence should be addressed; e-mail: dzama@vet.uz.ac.zw; *Present address: Department of Food Science and Animal Industries, Alabama Agricultural and Mechanical University, Normal, Alabama 35762, USA.

\section{Introduction}

The Texas A\&M University (TAMU) Beef Cattle Production model is perhaps the most comprehensive beef production simulation model (Chudleigh \& Cezar, 1982). It is a generalized model for simulating beef cattle production under a wide range of management schemes and environments with cattle differing widely in genotypes for size, growth and milk production. The model has been used to simulate beef cattle production under a wide range of climatic and management conditions in Guyana (Davis et al., 1976), Colombia (Cartwright et al., 1977), Venezuela (Ordonez, 1978), Botswana (ILCA, 1978), Tanzania (Sullivan et al., 1981), central Texas (Nelsen et al., 1978) and the mid-western United States (Notter et al., 1979a, b, c).

The treatment of genetics in the model (Sanders \& Cartwright, 1979a,b) is basic and rudimentary. Genetic production potentials are specified by mature weight, growth rate and milk yield. The beef cow-calf industry has become more complex, and the economic significance of breeding decisions has increased in the last two decades (Melton et al., 1992). New breeds of cattle such as the Brangus have been developed, and movement of germplasm between countries has increased since the advent of artificial insemination and embryo transfer allowing breeds such as the Tuli from Zimbabwe to be exported to Australia and the United States. Producers have continued to exploit within-breed variation for selection purposes. It is thus important that modelling efforts incorporate the heterogeneity that now exists in the industry. The introduction of genetic variation into the simulated population would allow researchers to study different selection objectives and help to draw up recommendations for beef producers. The objective of this study was to evaluate the modified TAMU Beef Cattle Production Computer Simulation Model by evaluating different selection strategies employing a restricted selection index in cattle breeds of varying mature sizes. 


\section{Materials and Methods}

The TAMU Beef Cattle Production model (Sanders \& Cartwright, 1979a,b) was used as a foundation for this study. The methodologies used in developing the genetic simulation model are based on principles and models of Middleton (1982), Tier (1984) and Falconer (1990). The classical model of quantitative genetics

$$
\sigma_{\mathrm{P}}^{2}=\sigma_{\mathrm{G}}^{2}+\sigma_{\mathrm{E}}^{2}
$$

where $\sigma_{\mathrm{P}}^{2}=$ phenotypic variance, $\sigma_{\mathrm{G}}^{2}=$ genotypic variance and $\sigma_{\mathrm{E}}^{2}=$ environmental variance was used. In addition, covariance between genotype and environment was assumed to be zero. The effects of dominance and epistasis were not modelled. Birthweight, yearling weight, mature weight and milk production were modelled as:

$$
\mathrm{Y}=\mu+\mathrm{G}+\mathrm{E}+\mathrm{T}
$$

where $\mathrm{Y}$ is the trait being modeled, $\mu$ is the population mean for the trait, $\mathrm{G}$ is the breeding value of the animal for the trait, $\mathrm{E}$ is the direct environmental effect on the animal and $\mathrm{T}$ is the temporary herd environmental effect common to all animals in that herd and in that year. The value of the offspring was the average of the additive components of the parents and a gamete sampling effect. The individual's breeding value was generated as follows:

$$
\mathrm{G}_{\mathrm{I}}=0.5 \mathrm{G}_{\mathrm{S}}+0.5 \mathrm{G}_{\mathrm{D}}+\mathrm{R}
$$

where $G_{S}$ is the breeding value of the sire, $G_{D}$ is the breeding value of the dam and $R$ is the random effect of the recombination of genes inherited from the parents. In terms of variances due to the additive effects of the genes, genotypic variance of the offspring was expressed as follows:

$$
\begin{aligned}
\sigma_{\mathrm{G}(\mathrm{I})}^{2} & =0.25 \sigma_{\mathrm{G}(\mathrm{S})}^{2}+0.25 \sigma_{\mathrm{G}(\mathrm{D})}^{2}+\sigma_{(\mathrm{R})}^{2} \\
& =0.25 \mathrm{~h}^{2} \sigma_{\mathrm{P}}^{2}+0.25 \mathrm{~h}^{2} \sigma_{\mathrm{P}}^{2}+\sigma_{(\mathrm{R})}^{2} \\
\text { since } \sigma_{\mathrm{G}^{2}}^{2} & =\mathrm{h}^{2} \sigma_{\mathrm{P}}^{2} \\
\text { therefore } \sigma_{(\mathrm{R})}^{2} & =0.5 \sigma_{\mathrm{G}}^{2} \\
\sigma_{(\mathrm{R})} & =0.5^{1 / 2} \sigma_{\mathrm{G}}
\end{aligned}
$$

where $h^{2}$ is the heritability of the trait and $\sigma_{\mathrm{G}}$ is the genetic standard deviation for the trait. The new equation for generation of breeding values becomes:

$$
\mathrm{G}_{\mathrm{I}}=0.5 \mathrm{G}_{\mathrm{S}}+0.5 \mathrm{G}_{\mathrm{D}}+\sigma_{\mathrm{G}} * \mathrm{D} * 0.5^{1 / 2}
$$

where $\mathrm{D}$ is the random multivariate normal deviate $(\mathrm{N}(0,1))$. To generate $\mathrm{D}$, a Cholesky decomposition was applied to a genetic matrix. The decomposed matrix was post-multiplied by a vector of pseudo-random deviates $\mathrm{N}(0,1)$ which returns a vector of correlated pseudo-random numbers. In matrix notation,

$\left[\begin{array}{l}\mathrm{D}_{1} \\ \mathrm{D}_{2} \\ \mathrm{D}_{3} \\ \mathrm{D}_{4}\end{array}\right]=\left[\begin{array}{llll}\tau_{1,1} & \tau_{1,2} & \tau_{1,3} & \tau_{1,4} \\ 0 & \tau_{2,2} & \tau_{2,3} & \tau_{2,4} \\ 0 & 0 & \tau_{3,3} & \tau_{3,4} \\ 0 & 0 & 0 & \tau_{4,4}\end{array}\right] *\left[\begin{array}{c}\Phi_{1} \\ \Phi_{2} \\ \Phi_{3} \\ \Phi_{4}\end{array}\right]$

where $D_{i}$ is the random multivariate normal deviate of the $i^{\text {th }}$ trait, $\tau_{i, j}$ results from Cholesky decomposition of genetic correlation matrix, $\Phi_{i}$ represents randomly selected pseudo-normal deviates for the $i^{\text {th }}$ trait and 1 , 2, 3, 4 represent birth weight, yearling weight, milk production, and mature weight respectively. Normally distributed random deviates were generated using algorithm AS 111 (Beasly \& Springer, 1977) while uniformly distributed random deviates were generated using algorithm AS 183 (Wichmann \& Hill, 1982). The latter algorithm generates identical random numbers from identical seeds regardless of computer type and has 
the desirable property that it works well on the extremes of distributions. Environmental variance was calculated as:

$$
\sigma_{\mathrm{E}}^{2}=\left(1-\mathrm{h}^{2}\right) * \sigma_{\mathrm{P}}^{2}
$$

Environmental correlation between traits $\mathrm{X}$ and $\mathrm{Y}$ was computed as:

$$
\mathrm{r}_{\mathrm{E}}=\left(\mathrm{r}_{\mathrm{P}}-\mathrm{h}_{\mathrm{x}} \mathrm{h}_{\mathrm{y}} \mathrm{r}_{\mathrm{G}}\right) /\left(\left(1-\mathrm{h}_{\mathrm{x}}^{2}\right) *\left(1-\mathrm{h}_{\mathrm{y}}^{2}\right)\right)^{1 / 2}
$$

where $r_{P}$ is the phenotypic correlation between traits $X$ and $Y ; r_{G}$ is the genetic correlation between traits $X$ and $\mathrm{Y}$; and $\mathrm{h}_{\mathrm{x}}$ and $\mathrm{h}_{\mathrm{y}}$ are the square roots of heritabilities for traits $\mathrm{X}$ and $\mathrm{Y}$ respectively. Environmental deviates for the $\mathrm{i}^{\text {th }}$ trait $\left(\mathrm{ED}_{\mathfrak{i}}\right)$ were generated as the product of a Cholesky decomposed matrix of environmental correlations and a vector of randomly selected pseudo-normal deviates. The direct environmental effect on the calf (E) was generated as:

Temporary herd effects $(\mathrm{T})$ were generated as follows:

$$
\mathrm{E}=\mathrm{ED} * \sigma_{\mathrm{E}} .
$$

$$
\mathrm{T}=\mathrm{ED} * \sigma_{\mathrm{T}}
$$

where $\sigma_{\mathrm{T}}=$ temporary herd effects standard deviation, which is computed as the product of the environmental standard deviation and a temporary herd effect standard deviation factor (TSDF). TSDF is the proportion of the direct environmental standard deviation that is used to set temporary herd environmental effects for a trait and is specified in the input files. The following assumptions apply to the principles outlined above: 1) sires and dams, and genetic and environmental effects are independent, i.e. $\left.\operatorname{cov}\left(\mathrm{G}_{\mathrm{S}}, \mathrm{G}_{\mathrm{D}}\right)=0, \operatorname{cov}(\mathrm{G}, \mathrm{E})=0 ; 2\right)$ $\mathrm{E}(\mathrm{R})=\mathrm{E}(\mathrm{T})=0 ; 3)$ genetic effects are normally distributed and 4) the genetic variance is constant throughout the simulation since all the four traits under investigation are thought to be controlled by many loci. Under this condition selection will probably not cause a decline in genetic variance unless it is practiced at very high intensities and for many generations. A restricted selection index described by Yamada et al. (1975) and Itoh \& Yamada (1988) was used. It is denoted by:

$$
\mathrm{I}=\mathrm{b}^{\prime} \mathrm{x}
$$

where $\mathrm{x}=\mathrm{an} \mathrm{n} x 1$ vector of known phenotypic values and $\mathrm{b}=\mathrm{an} \mathrm{n} \times 1$ vector of weighting factors. In addition, $\mathrm{Q}=$ an $\mathrm{m} \times 1$ vector containing the desired relative genetic changes, $\mathrm{G}=\mathrm{n} \times \mathrm{m}$ matrix of the genetic variance-covariance of the traits and $\mathrm{P}=\mathrm{n} \mathrm{x} \mathrm{n}$ matrix of the phenotypic variance-covariance of the traits in $\mathrm{x}$. The expected gains after one generation of selection are:

$$
\mathrm{E}(\Delta \mathrm{g})=i \mathrm{G}^{\prime} \mathrm{b} / \sigma_{\mathrm{I}}
$$

where $i$ is the intensity of selection and $\sigma_{\mathrm{I}}=\left(\mathrm{b}^{\prime} \mathrm{Pb}\right)$, the standard deviation of the index. The overall selection intensity on a restricted selection index for the whole population was computed as:

$$
i_{\mathrm{I}}=\mathrm{y} *\left(\mathrm{~b}^{\prime} \mathrm{Pb}\right)^{1 / 2} / \mathrm{t}
$$

where $y$ is the average generation interval in years and $t$ is the time in years. Maximizing $\mathrm{E}(\Delta \mathrm{g})$ or minimizing $\sigma_{\mathrm{I}}$ as shown by Itoh and Yamada (1986) yields the following solution:

$$
\mathrm{b}=\mathrm{P}^{-1} \mathrm{G}\left(\mathrm{G}^{\prime} \mathrm{P}^{-1} \mathrm{G}\right)^{-1} \mathrm{Q}
$$

When $\mathrm{G}$ is singular, a generalised inverse has to be used and no unique solution exists. This may occur when $\mathrm{n}<\mathrm{m}$. When $\mathrm{n}>\mathrm{m}, \mathrm{G}$ is non-singular and unique solution for $\mathrm{b}$ exists. In the present study $\mathrm{n}=\mathrm{m}$ and since

the solution simplifies to:

$$
\left(\mathrm{G}^{\prime} \mathrm{P}^{-1} \mathrm{G}\right)^{-1}=\left(\mathrm{P}^{-1} \mathrm{G}\right)^{-1} \mathrm{G}^{-1}
$$

$$
\mathrm{b}=\mathrm{G}^{-1} \mathrm{Q}
$$

The model was expanded to include breeding bulls, artificial insemination bulls and replacement sires. It also simulates dystocia as measured by a calving difficulty score (CDS). Dzama (1993) and Dzama et al. (1994) have described the modified model in detail. Tables 1, 2 and 3 contain the genotypic and phenotypic parameters required by the simulation. These parameters were based on a summary of genetic and environmental statistics of beef cattle compiled by Woldehawariate et al. (1977). All the genetic and phenotypic parameters are contained in an input file and can thus be changed to simulate populations with 
different parameters. The variance-covariance structure was assumed to be constant throughout the entire simulation period. Although population genetic parameters may change theoretically during selection (Bulmer, 1971), there are no reports of this in the literature.

Table 1 Genotypic and phenotypic correlations between traits used in the model. Genotypic correlations are shown above the diagonal, heritabilities on the diagonal and phenotypic correlations below the diagonal.

\begin{tabular}{|c|c|c|c|c|c|}
\hline Trait & Birth & weight & Yearling weight & Mature weight & Milk production \\
\hline Birth weight & & 0.40 & 0.50 & 0.10 & 0.60 \\
\hline Yearling weight & & 0.45 & 0.30 & 0.70 & 0.10 \\
\hline Mature weight & & 0.40 & 0.50 & 0.35 & 0.20 \\
\hline Milk production & & 0.05 & 0.25 & 0.10 & 0.30 \\
\hline
\end{tabular}

Table 2 Genetic variance-covariance structure of birth weight, mature weight, milk production and yearling weight traits used in the simulation model. Variances are given on the diagonal and covariances above the diagonal.

\begin{tabular}{lcclc}
\hline & BWT & MWT & MP & YWT \\
\hline Birth weight (BWT) & 6 & 26 & 0.47 & 17.32 \\
Mature weight (MWT) & & 320 & 6.79 & 177.09 \\
Milk production (MP) & & & 3.6 & 2.68 \\
Yearling weight (YWT) & & & & 200 \\
\hline
\end{tabular}

Table 3 Phenotypic variance-covariance structure of birth weight, mature weight, milk production and yearling weight traits used in the simulation model. Variances are given on the diagonal and covariances below the diagonal.

\begin{tabular}{llcll}
\hline & BWT & MWT & MP & YWT \\
\hline Birth weight (BWT) & 15 & & & \\
Mature weight (MWT) & 43.82 & 800 & & \\
Milk production (MP) & 6.71 & 9.80 & 12 & \\
Yearling weight (YWT) & 38.97 & 316.23 & 19.37 & 500 \\
\hline
\end{tabular}

In experiment 1 a restricted selection index for birth weight and yearling weight $(0.47 \mathrm{BWT}+0.0089 \mathrm{YWT})$ was applied to a herd of small-to-moderate size cattle, e.g. Tuli or Hereford, for twenty years. Table 4 contains the herd composition and population parameters of a small-to-moderate sized breed of the starting population at steady state.

Table 4 Herd composition and parameters of the starting population of a small to moderate-sized breed

\begin{tabular}{|c|c|c|c|c|c|c|}
\hline Class $^{\mathrm{a}}$ & $\mathrm{n}$ & $\begin{array}{c}\text { Birth weight } \\
(\mathrm{kg})\end{array}$ & $\begin{array}{c}\text { Yearling } \\
\text { weight }(\mathrm{kg})\end{array}$ & $\begin{array}{c}\text { Mature weight } \\
(\mathrm{kg})\end{array}$ & $\begin{array}{c}\text { Milk Production } \\
(\mathrm{kg})\end{array}$ & CDS \\
\hline $\mathrm{BC}$ & 13 & 29.29 & 285.40 & 505.80 & 10.42 & 1.05 \\
\hline RH & 29 & 30.21 & 291.80 & & & 1.12 \\
\hline $\mathrm{HC}$ & 83 & 30.05 & 284.95 & & & \\
\hline BB & 11 & 31.97 & 310.84 & 777.81 & & \\
\hline $\mathrm{RB}$ & 5 & 31.26 & 309.88 & & & \\
\hline $\mathrm{BuC}$ & 84 & 32.11 & 301.61 & & & \\
\hline
\end{tabular}

The base population at steady state was simulated from a seed herd in which all the animals were unrelated. The herd composition was maintained at comparable levels throughout the experimental period. The breed has 
moderate milking abilities and low levels of dystocia as reflected by the calving difficulty score. The goal (Q vector) of the index was to increase birth weight by $3 \mathrm{~kg}$ and yearling weight by $10 \mathrm{~kg}$ over a period of twenty years $([Q=310])$. In beef cattle breeding, twenty years is generally regarded as medium term selection (Jansen, 1985). Selection based on an index was carried out on bulls, heifers and cows. Bulls were selected from the bull calves born in the herd. Even though inbreeding was not simulated, bulls were mated to females to whom they were least related. Bulls were subjected to a two-stage selection based on the index. Initially only the top five bulls were selected as replacement bulls at 12 months of age. At the beginning of the breeding season replacement bulls were moved into the breeding bull class and thereafter the number of bulls required was computed. The number of bulls needed was based on a mating ratio of one bull to 25 females plus a spare bull. At this stage the number of bulls needed was selected from the available pool of breeding bulls based on an index applied across generations. The remaining bulls were sold. Replacement heifers were selected from heifer calves born within the herd. The top 30 heifer calves were selected to become replacement heifers at weaning based on their indices. The selection intensity on the females was lower than that on bulls, as is normal industry practice. Table 5 shows a summary of the indices, the standard deviation of the indices, the selection objectives, the selection intensity and the expected change per year in birth weight and yearling weight.

Table 5 Summary of selection objectives and selection indices used and their attributes

\begin{tabular}{|c|c|c|c|c|c|c|}
\hline \multirow[t]{2}{*}{ Selection index } & \multirow{2}{*}{$\begin{array}{l}\text { Index standard } \\
\text { deviation }\end{array}$} & \multicolumn{2}{|c|}{$Q$ vector } & \multirow{2}{*}{$\begin{array}{l}\text { Selection } \\
\text { intensity } b\end{array}$} & \multicolumn{2}{|c|}{$\mathrm{E}(\Delta \mathrm{g}) / \mathrm{yr}$} \\
\hline & & BWT & YWT $^{\mathrm{a}}$ & & BWT & YWT $^{\mathrm{c}}$ \\
\hline $0.47 \mathrm{BWT}+0.0089 \mathrm{YWT}$ & 1.93 & 3 & 10 & 1.515 & 0.47 & 1.57 \\
\hline$-0.51 \mathrm{BWT}+0.1192 \mathrm{YWT}$ & 2.51 & -1 & 15 & 1.391 & -0.11 & 1.66 \\
\hline
\end{tabular}

${ }^{\mathrm{a}}$ YWT $=$ yearling weight; ${ }^{\mathrm{b}}$ The intensity that would be required to make the desired change in 20 years; ${ }^{\mathrm{c}}$ Based on these intensities.

Experiment 2 used an index (-0.51BWT $+0.1192 \mathrm{YWT})$ depicting antagonistic selection in a large breed, e.g. Simmental or Charolais. The goal was to decrease birth weight by $1 \mathrm{~kg}$ and increase yearling weight by $15 \mathrm{~kg}$. Table 6 contains the starting herd composition and population parameters of a large-sized breed at steady state. The breed produces considerably more milk compared to the smaller breed used in the previous experiment. The birth weight was higher and significant levels of calving difficulties occurred in this breed. The major goal in this set was to attempt to increase yearling weight while reducing birth weight and consequently dystocia. The breeding management is the same as practised in Experiment 1.

Table 6 Herd composition and parameters of the starting population of a large-sized breed

\begin{tabular}{llrrrrr}
\hline Class $^{\mathrm{a}}$ & $\mathrm{n}$ & Birth weight $(\mathrm{kg})$ & $\begin{array}{c}\text { Yearling } \\
\text { weight }(\mathrm{kg})\end{array}$ & $\begin{array}{c}\text { Mature weight } \\
(\mathrm{kg})\end{array}$ & $\begin{array}{c}\text { Milk Production } \\
(\mathrm{kg})\end{array}$ & $\mathrm{CDS}$ \\
\hline $\mathrm{BC}$ & 90 & 34.33 & 303.50 & 596.31 & 14.13 & 1.09 \\
$\mathrm{RH}$ & 31 & 34.94 & 311.23 & & & 1.21 \\
$\mathrm{HC}$ & 57 & 34.76 & 307.06 & & & \\
$\mathrm{BB}$ & 10 & 36.20 & 320.34 & 913.73 & & \\
$\mathrm{RB}$ & 5 & 38.22 & 321.82 & & & \\
$\mathrm{BuC}$ & 53 & 37.54 & 327.67 & & & \\
\hline
\end{tabular}

${ }^{\mathrm{a}} \mathrm{BC}=$ Breeding cows, $\mathrm{RH}=$ Replacement heifers, $\mathrm{HC}=$ Heifer calves, $\mathrm{BB}=$ Breeding bulls, $\mathrm{BuC}=\mathrm{Bull}$ calves, $\mathrm{RB}=$ replacement bulls.

In both studies dystocia was measured as a calving difficulty score which ranged from 1 to $4 ; 1=$ no calving difficulty; $2=$ minimal difficulty; $3=$ hard pull requiring mechanical assistance; and $4=$ severe difficulty requiring caesarean section. Dzama (1993) described the detailed computation of CDS. Each experiment was replicated ten times. The output was analysed using the General Linear Model procedure of SAS (1996). 


\section{Results and Discussion}

The birth weight, yearling weight and mature weight of the control population for the small-moderate breed remained unchanged over the 20-year period. The results of the regression of birth weight, yearling weight, milk production and mature size on time for experiment 1 ( $[\mathrm{Q}=310])$ are presented in Table 7. Figure 1 shows the plot of birth weight $v s$. time for 20 years for females (replacement heifers, breeding cows and heifer calves). Figure 2 shows the change in male (breeding bulls, replacement bulls and bull calves) birth weight over the same period of time.

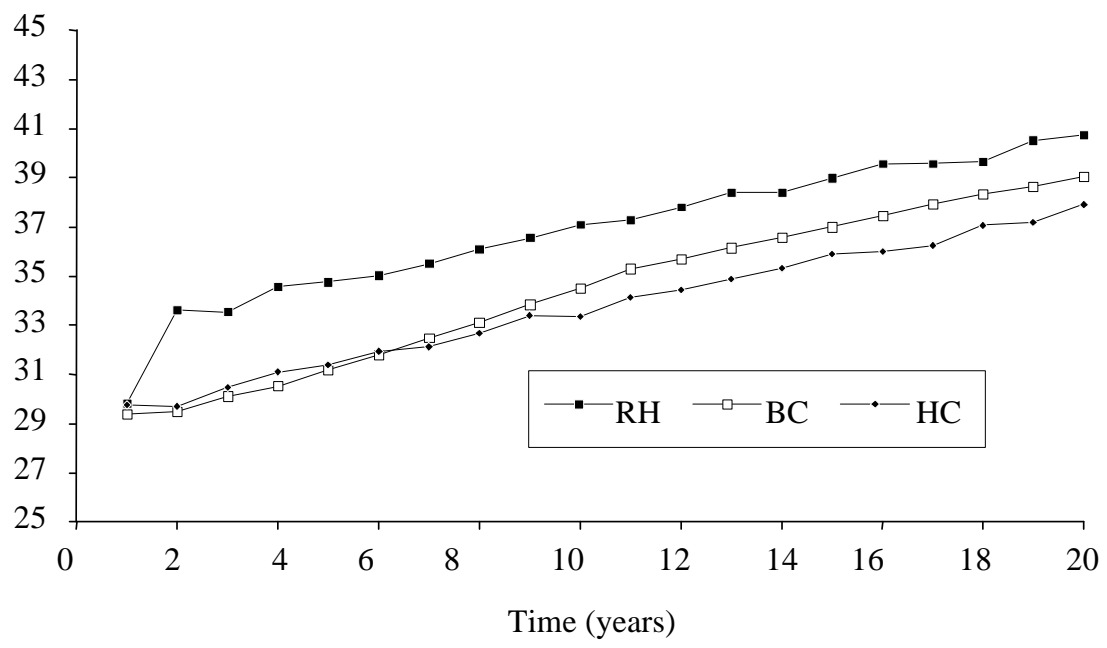

Figure 1 Simulated female selection response in birth weight when selection is based on a restricted index $(\mathrm{Q}$ $=\left[\begin{array}{ll}3 & 10\end{array}\right]$ ) for birth weight and yearling weight within a small-to-moderate size breed. $\mathrm{RH}=$ replacement heifers, $\mathrm{BC}=$ breeding cows, $\mathrm{HC}=$ heifer calves

Table 7 Means and standard errors of regression statistics for response to selection per year in a small-tomoderate size breed using a restricted selection index $\left(Q=\left[\begin{array}{ll}3 & 10\end{array}\right]\right)$ for different classes of animals ${ }^{\mathrm{a}}$

\begin{tabular}{llcccccc}
\hline Trait & Class & $\mathrm{a}$ & $\mathrm{SE}$ & $\mathrm{b}$ & $\mathrm{SE}$ & $\mathrm{R}^{2}$ & F-value \\
\hline Birth & $\mathrm{R}$ & 36.68 & 0.512 & 0.511 & 0.040 & 0.902 & $165.24^{* *}$ \\
weight (kg) & $\mathrm{BB}$ & 33.28 & 0.881 & 0.749 & 0.068 & 0.869 & $119.82^{* *}$ \\
& $\mathrm{BuC}$ & 30.66 & 0.123 & 0.445 & 0.010 & 0.992 & $2173.84^{* *}$ \\
& $\mathrm{RH}$ & 31.64 & 0.371 & 0.456 & 0.029 & 0.933 & $249.35^{* *}$ \\
& $\mathrm{BC}$ & 28.17 & 0.160 & 0.545 & 0.012 & 0.991 & $1924.83^{* *}$ \\
& $\mathrm{HC}$ & 28.82 & 0.089 & 0.429 & 0.007 & 0.995 & $3813.96^{* *}$ \\
Yearling & & & & & & & \\
weight (kg) & $\mathrm{RH}$ & 293.07 & 1.622 & 1.509 & 0.126 & 0.888 & $143.26^{* *}$ \\
& $\mathrm{BC}$ & 282.47 & 0.576 & 1.734 & 0.045 & 0.988 & $1498.92^{* *}$ \\
& $\mathrm{HC}$ & 285.01 & 0.395 & 1.362 & 0.031 & 0.991 & $1968.99^{* *}$ \\
& $\mathrm{RB}$ & 322.20 & 2.043 & 1.581 & 0.159 & 0.846 & $99.04^{* *}$ \\
& $\mathrm{BB}$ & 314.18 & 2.823 & 2.147 & 0.219 & 0.842 & $95.72^{* *}$ \\
Mature & $\mathrm{BuC}$ & 302.80 & 0498 & 1.407 & 0.039 & 0.987 & $1322.05^{* *}$ \\
weight (kg) & & & & & & & \\
& $\mathrm{BB}$ & 778.71 & 3.550 & 4.318 & 0.276 & 0.932 & $244.81^{* *}$ \\
Milk production (kg/day) & $\mathrm{BC}$ & 10.80 & 0.040 & 0.054 & 0.003 & 0.952 & $13077.05^{* *}$ \\
\hline
\end{tabular}

${ }^{\mathrm{a}}$ Parameter estimates from model: $\mathrm{Y}=\mathrm{a}+\mathrm{bX} ;{ }_{\mathrm{BC}}=$ Breeding cows, $\mathrm{RH}=$ Replacement heifers, $\mathrm{HC}=\mathrm{Heifer}$ calves, $\mathrm{BB}=$ Breeding bulls, $\mathrm{RB}=$ replacement bulls, $\mathrm{BuC}=$ Bull calves; $* * \mathrm{P}<0.001 ; * \mathrm{P}<0.05$ 


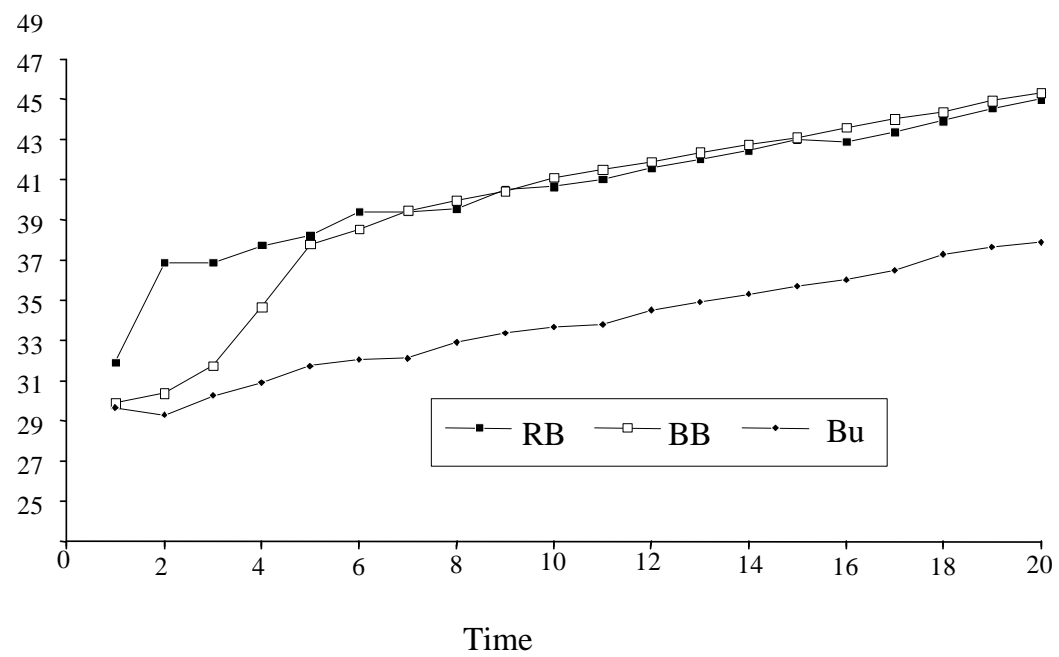

Figure 2 Simulated male selection response in birth weight when selection is based on a restricted index $(\mathrm{Q}=$ [3 10]) for birth weight and yearling weight within a small to moderate-sized breed. RB = replacement bulls, $\mathrm{BB}=$ breeding bulls, $\mathrm{BuC}=$ bull calves

Replacement heifers selected had larger birth weights $(\mathrm{P}<0.05)$ than both breeding cows and heifer calves for all years except year one. After approximately one generation of selection, breeding cows switched ranks with heifer calves. This is because of the selection carried out on replacement heifers. Breeding bulls exhibited the largest change in birth weight per year $(0.749 \pm 0.068)$ since they were subjected to two-stage selection and hence higher selection intensity. The annual response for breeding bulls as measured by the regression coefficient may be exaggerated because the first five years consisted of a very rapid increase in selection response followed by a steady increase where the curve was almost parallel to that of replacement bulls. On the average three replacement bulls became breeding bulls each year. All regressions are highly significant $(\mathrm{P}<0.001)$. There is a general agreement between the expected genetic gain per year in Table 5 and the realised response in Table 7.

Figures 3 and 4 show yearling-weight selection responses in females and males, respectively. All class regressions of yearling weight on time were highly significant $(\mathrm{P}<0.001)$. As with birth weight, replacement heifers exhibited the largest weaning weights, and cows eventually overtook heifer calves after five years of selection. Except for the first four years of selection, breeding bulls and replacement bulls had similar yearling weights. However, breeding bulls still had the highest gain per year of all classes.

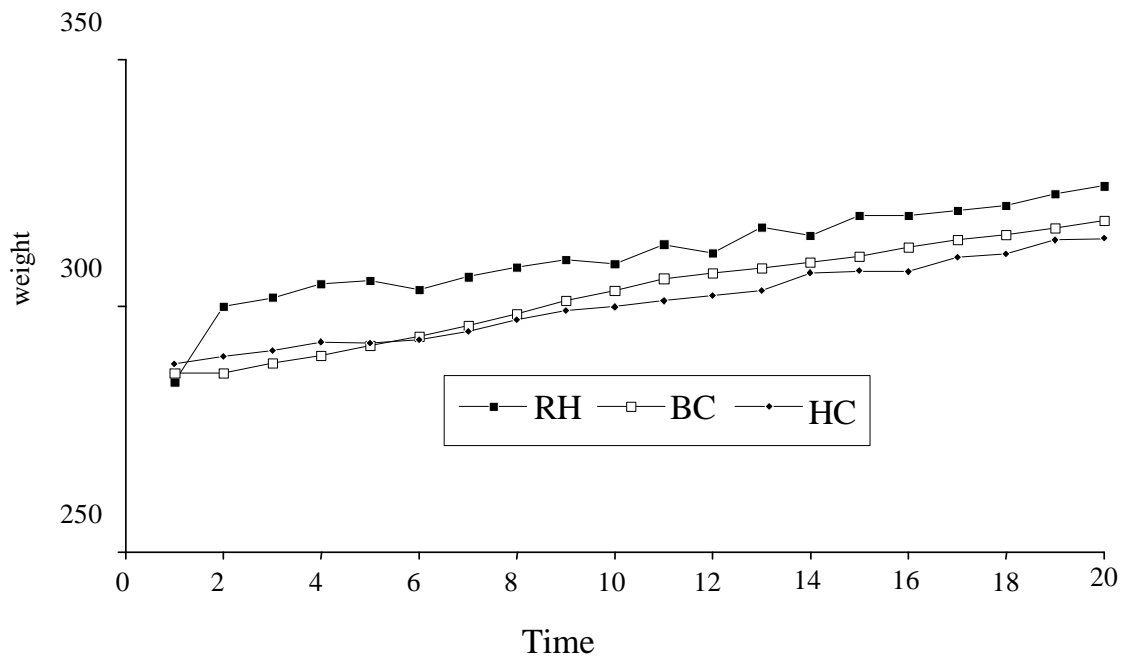

Figure 3 Simulated female selection response in yearling weight when selection is based on a restricted index $\left(\mathrm{Q}=\left[\begin{array}{l}310\end{array}\right]\right)$ for birth weight and yearling weight within a small to moderate-sized breed. $\mathrm{RH}=$ replacement heifers, $\mathrm{BC}=$ breeding cows, $\mathrm{HC}=$ heifer calves 


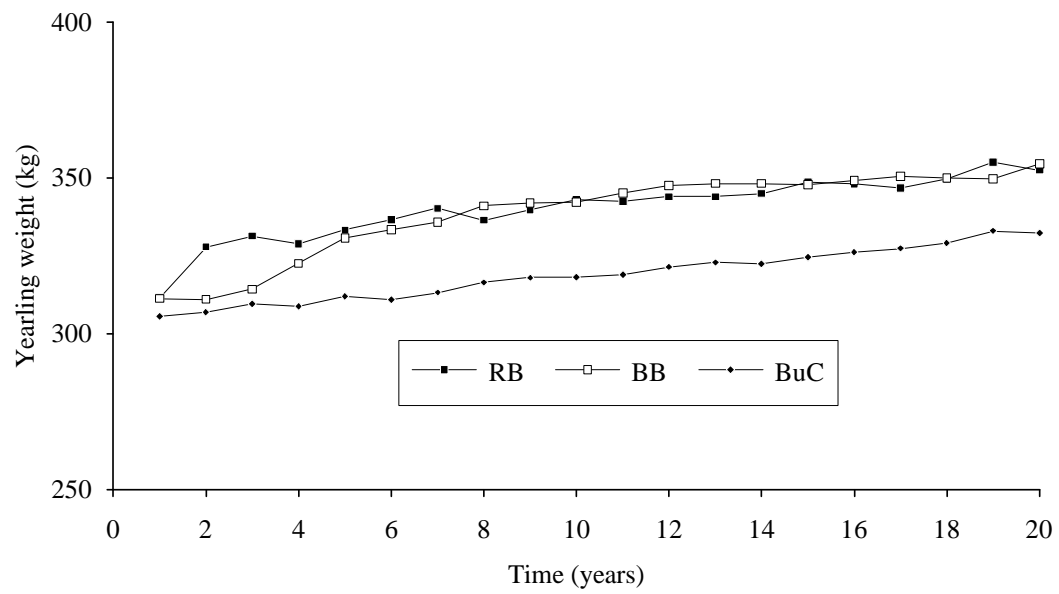

Figure 4 Simulated male selection response in yearling weight when selection is based on a restricted index $\left(\mathrm{Q}=\left[\begin{array}{ll}3 & 10\end{array}\right]\right)$ for birth weight and yearling weight within a small to moderate-sized breed. $\mathrm{RB}=$ replacement bulls, $\mathrm{BB}=$ breeding bulls, $\mathrm{BuC}=$ bull calves

Mature weight of breeding cows increased at a rate of $2.512 \mathrm{~kg} / \mathrm{year}$ to $553.74 \mathrm{~kg}$ while it increased by 4.318 in breeding bulls to reach $863.32 \mathrm{~kg}$ in year $20(\mathrm{P}<0.001)$. The higher intensity of selection practised among males was still reflected at maturity. In the base population, dystocia levels were low but increased as birth weight increased from $30.70 \mathrm{~kg}$ in the base population to $38.95 \mathrm{~kg}$ in year 20. The mean CDS score increased from 1.12 in the starting population to 1.75 , implying that the number of heifers requiring at least some assistance had increased. Experiment 2 used an index representing antagonistic selection. The aim was to decrease birth weight by one $\mathrm{kg}$ and at the same time increase yearling weight by 15 $\mathrm{kg}$. Regression statistics are shown in Table 8.

Table 8 Means and standard errors of regression statistics for responses to selection per year in a large-sized breed using a restricted selection index $\left(\mathrm{Q}=\left[\begin{array}{ll}-1 & 15\end{array}\right]\right)$ for birth weight, yearling weight, mature weight and milk production for different classes of animals ${ }^{\mathrm{a}}$

\begin{tabular}{|c|c|c|c|c|c|c|c|}
\hline Trait & Class $^{b}$ & A & SE & $\mathrm{b}$ & SE & $\mathrm{R}^{2}$ & F-value \\
\hline \multirow{6}{*}{$\begin{array}{l}\text { Birth } \\
\text { weight }(\mathrm{kg})\end{array}$} & $\mathrm{RB}$ & 35.59 & 0.575 & -0.171 & 0.045 & 0.449 & $14.67 *$ \\
\hline & $\mathrm{BB}$ & 36.36 & 0.322 & -0.250 & 0.025 & 0.847 & $99.81 * *$ \\
\hline & $\mathrm{BuC}$ & 37.26 & 0.161 & -0.155 & 0.013 & 0.894 & $152.52 * *$ \\
\hline & RH & 33.96 & 0.146 & -0.123 & 0.011 & 0.868 & $118.66 * *$ \\
\hline & $\mathrm{BC}$ & 35.30 & 0.084 & -0.180 & 0.007 & 0.977 & $759.40 * *$ \\
\hline & $\mathrm{HC}$ & 34.92 & 0.107 & -0.135 & 0.008 & 0.936 & $261.79 * *$ \\
\hline \multirow{6}{*}{$\begin{array}{l}\text { Yearling } \\
\text { weight }(\mathrm{kg})\end{array}$} & RH & 305.63 & 1.752 & 1.967 & 0.136 & 0.921 & $208.56 * *$ \\
\hline & $\mathrm{BC}$ & 297.68 & 0.620 & 1.886 & 0.048 & 0.988 & $1529.50 * *$ \\
\hline & $\mathrm{HC}$ & 298.88 & 0.592 & 1.657 & 0.046 & 0.986 & $1295.30 * *$ \\
\hline & $\mathrm{RB}$ & 341.76 & 1.205 & 2.011 & 0.094 & 0.962 & $460.91 * *$ \\
\hline & BB & 327.23 & 3.636 & 3.050 & 0.283 & 0.866 & $116.44 * *$ \\
\hline & $\mathrm{BuC}$ & 316.55 & 0.435 & 1.791 & 0.034 & 0.994 & $2812.61 * *$ \\
\hline \multirow{2}{*}{$\begin{array}{l}\text { Mature } \\
\text { weight }(\mathrm{kg})\end{array}$} & $\mathrm{BB}$ & 910.69 & 2.035 & 1.561 & 0.158 & 0.844 & $97.29 * *$ \\
\hline & $\mathrm{BC}$ & 597.25 & 0.300 & 0.966 & 0.023 & 0.990 & $1715.74 * *$ \\
\hline $\begin{array}{l}\text { Milk } \\
\text { Production ( }\end{array}$ & $\mathrm{BC}$ & 13.70 & 0.073 & 0.033 & 0.006 & 0.658 & $34.70 * *$ \\
\hline
\end{tabular}

${ }^{\mathrm{a}}$ Parameter estimates from model: $\mathrm{Y}=\mathrm{a}+\mathrm{bX} ;{ }^{\mathrm{b} B}=$ replacement bulls, $\mathrm{BC}=$ Breeding cows, $\mathrm{RH}=$ Replacement heifers, $\mathrm{HC}=$ Heifer calves, $\mathrm{BB}=$ Breeding bulls, $\mathrm{BuC}=$ Bull calves; $* * \mathrm{P}<0.001 ; * \mathrm{P}<0.05$ 
As in experiment 1, the control population's birth weight, yearling weight and mature weight remained unchanged over the 20-year period All classes showed a decline in birth weight significant to at least the 0.05 level. The sudden drop in birth weight for replacement bulls occurred because emphasis was put on bulls with low birth weights. Dystocia levels declined $(\mathrm{P}<0.001)$ as expected. Although birth weight decreased in all classes, there were significant responses per year in yearling weight, as shown in Figure 5.

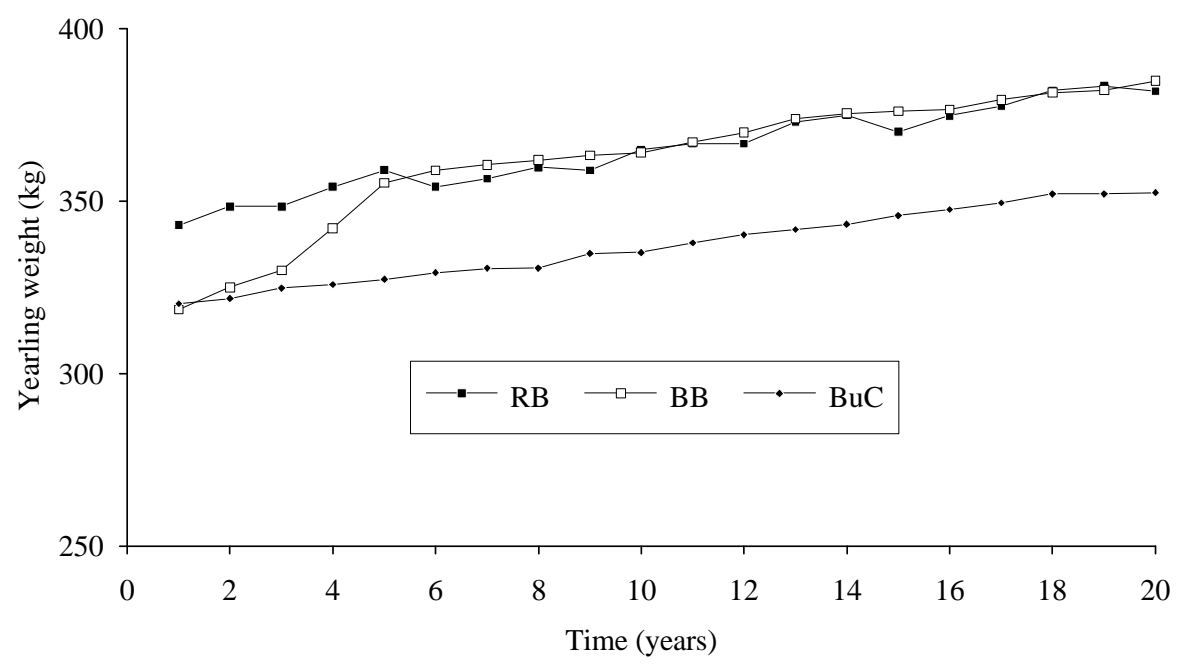

Figure 5 Simulated male selection response in yearling weight when selection is based on a restricted index (Q $\left.=\left[\begin{array}{ll}-1 & 15\end{array}\right]\right)$ for birth weight and yearling weight within a large-sized breed. $\mathrm{RB}=$ replacement bulls, $\mathrm{BB}=$ breeding bulls, $\mathrm{BuC}=$ bull calves

The response per year for experiment 2 was smaller than for experiment 1 . This is probably because of antagonistic selection for traits that are genetically positively correlated. There was also a correlated response in milk production $(\mathrm{P}<0.001)$ and mature weight $(\mathrm{P}<0.001)$, albeit smaller than in experiment 1 . The CDS declined from 1.21 in the starting population to 1.05 ( $\mathrm{P}<0.001)$. With the help of the appropriate economic indices, a breeder would be able use this data to decide whether to forego some of the potential gains in yearling weight in order to offset losses due to dystocia. As birth weight increased, dystocia levels for experiment 1 approached levels similar to those found in larger breeds such as the one used in experiment 2 . This is consistent with the findings of Berger et al. (1992). They concluded that dystocia patterns normally associated with larger breeds such as the Simmental and Charolais are also prevalent in smaller breeds such as the Angus and Hereford in the United States beef industry. This is probably because there has been a conscious effort by many breeders of what may have been previously known as small breeds such as the Angus to increase weight and size traits such as mature weight (T.C. Cartwright, personal communication). Lamb et al. (1993) reported that means for the American Angus breed increased from 1970 to 1984 by $16.6 \%$ for birth weight, by $21 \%$ for weaning weight, by $12.2 \%$ for yearling weight and by $7 \%$ for mature weight. The corresponding values for the Simmental breed were $-1.6 \%,-2.6 \%, 12 \%$ and $6 \%$. Even though these changes were not achieved by selection alone, there is a general similarity with the changes predicted by the current simulation study.

In both experiments 1 and 2, there was general agreement between the realised responses (change per year for birth weight and yearling weight computed from the regressions) and those computed a priori. However, in some cases the realised response was higher than the expected response. This is probably because the selection intensities used in the experiments tended to be higher than the calculated intensities required for the desired changes specified in the $\mathrm{Q}$ vector. In addition, the fluctuations in response from year to year, especially in classes with fewer animals such as breeding bulls, may be a contributing factor. There are limits to the amount of restriction a breeder can impose, especially when traits are genetically and phenotypically correlated. This was demonstrated by the increase in birth weight beyond the 3-kg restriction set by the index. For optimum response there must be biological compatibility between selection goals and 
genetic correlations between traits in the selection index (Eisen, 1977). Lin (1985) concluded that severe restrictions would also require unrealistically high selection intensities.

There is a paucity of data on the practical application of the restricted index in beef cattle. Practical application of this type of index has been implemented in mice (Eisen, 1977) and in poultry (Nordskog et al., 1974). Urick et al. (1984) studied two lines of inbred Hereford cattle selected for high yearling weight phenotype alone or for high yearling weight and low birth weight. Data available after five years of selection showed a $5.0 \%$ difference in average birth weight between the two herds and a $1.8 \%$ difference in yearling weight for bull calves, while heifers showed inconsistent differences. The number of heifers that required assistance during parturition decreased by $6 \%$. These findings do not fully agree with the results of the current study, perhaps because the two groups of bulls used in the study came from distinctly different lines. The selection goals and intensities were not specified and the starting population sires were from two distinct lines. Wilson \& Willham (1986) reported within herd genetic, phenotypic and environmental trends in 20 Angus herds throughout the United States for weaning weight. The general trends in some herds where selection was utilised agree with the findings of the current study.

\section{Conclusions}

The modified TAMU Beef Cattle Production model offers breeders an opportunity to compare different selection strategies and evaluate different breeding plans. In addition, the restricted selection index allows manipulation of traits that are genetically correlated and at the same time avoids the problem of estimating economic weights. In particular, the model offers an opportunity to restrict birth weight while increasing yearling weight.

\section{References}

Beasley, J.D. \& Springer, S.G., 1977. The percentage points of the normal distribution. Appl. Stat. 26, 118121.

Berger, P.J., Cubas, A.C., Koehler, K.J. \& Healy, M.H., 1992. Factors affecting dystocia and early calf mortality in Angus cows and heifers. J. Anim. Sci. 70, 1775-1786.

Bulmer, M.G., 1971. The effect of selection on genetic variability. American Naturalist 105, 201-211.

Cartwright, T.C., Gomez, F.G., Sanders, J.O. \& Nelsen. T.C., 1977. Simulated milk-beef production systems in Colombia. J. Anim. Sci. 45 (Suppl. 1), 13.

Chudleigh, P.D. \& Cezar, I.M., 1982. A review of bioeconomic simulation models of beef production systems and suggestions for methodological development. Agric. Systems 10, 273.

Dzama, K., Walter, J.P., Ruvuna, F., Sanders, J.O. \& Pierce, W.B., 1994. Incorporation of genetic concepts into a general cattle production system model. Proc. $5^{\text {th }}$ World Congr. Genet. Appl. Livest. Prod. 17, 300-303.

Dzama, K., 1993. Genetic Simulation of Beef Cattle Production for Growth and Milk Production. PhD Thesis, Texas A\&M University, College Station, TX, USA.

Eisen, E.J., 1977. Antagonistic selection index results with mice. Proceedings of the International Conference on Quantitative Genetics. Iowa State University, Ames, Iowa, USA. pp. 117-139.

Falconer, D.S., 1990. Introduction to Quantitative Genetics. Longman Inc., New York.

Jansen, G.B., 1985. Selection and mating strategies to improve quadratic merit. PhD. Dissertation. University of Guelph, Ontario, Canada.

International Livestock Centre for Africa. (ILCA)., 1978. Mathematical modeling of livestock production systems: Applications of the Texas A\&M University beef cattle production model to Botswana. ILCA, Addis Ababa, Ethiopia.

Itoh, Y. \& Yamada, Y., 1986. Re-examination of selection index for desired gains. Genet. Sel. Evol. 18, 499504.

Itoh, Y. \& Yamada, Y., 1988. Selection indices for desired relative genetic gains with inequality constraints. Theoretical and Applied Genetics 75, 731-735.

Lamb, M.A. Tess, M.W. \& Robison, O.W., 1993. Evaluation of mating systems involving five breeds for integrated beef production systems: IV. Accounting for variability and genetic trends. J. Anim. Sci. 71, 587. 
Melton, B.E., Colette, W.A. \& Smith, K.L., 1992. A framework for determining relative economic values of alternative beef breeds and crosses: An application to commercial cow calf production in the Texas panhandle. Texas Agricultural Experiment Station Bulletin, Texas A\&M University, College Station, TX, USA.

Middleton, B.K., 1982. Echo/SEP User's guide. Iowa State University, Ames, Iowa.

Nelsen, T.C., Cartwright, T.C. \& Sanders, J.O., 1978. Simulated production efficiencies from biologically different cattle in different environments. J. Anim. Sci. 47 (Suppl. 1), 60.

Notter, D.R., Sanders, J.O., Dickerson, G.E., Smith, G.M. \& Cartwright, T.C., 1979a. Simulated efficiency of beef production for a Midwestern cow-calf-feedlot management system. I. Milk production. J. Anim. Sci. 49, 70-82.

Notter, D.R., Sanders, J.O., Dickerson, G.E., Smith, G.M. \& Cartwright, T.C., 1979b. Simulated efficiency of beef production for a Midwestern cow-calf-feedlot management system. II. Mature body size. J. Anim. Sci. 49, 83-91.

Notter, D.R., Sanders, J.O., Dickerson, G.E., Smith, G.M. \& Cartwright, T.C., 1979c. Simulated efficiency of beef production for a Midwestern cow-calf-feedlot management system. III. Crossbreeding systems. J. Anim. Sci. 49, 92-102.

Nordskog, A.W., Tollman, H.S., Casey, W.D. and Lin, C.Y., 1974. Selection in small populations of chickens. Poultry Sci. 53, 1188.

Ordonez, J., 1978. Systems analysis of beef production in the Western High Plains of Venezuela. PhD Dissertation, Texas A\&M University, College Station, Texas, USA

Sanders, J.O. \& Cartwright, T.C., 1979a. A general cattle production systems model. I. Structure of the model. Agric. Systems 4, 217-227.

Sanders, J.O. \& Cartwright, T.C., 1979b. A general cattle production systems model. II. Procedures used for simulating animal performance. Agric. Systems 4, 289-309.

SAS., 1996. SAS User's Guide: Statistics. SAS Institute Inc., Cary, NC, USA.

Sullivan, G.M., Cartwright, T.C. \& Farris, D.E., 1981. Simulation of production systems in East Africa by use of interfaced forage and cattle models. Agric. Systems 7, 245-265.

Tier, B., 1984. A Beef Cattle Breeding Simulation Program Manual for Users. University of New England, Armidale, Australia.

Urick, J.J., Reynolds, W.L. \& Bellows, R.A., 1984. A selection experiment to control birth weight in beef cattle. Research in Action. Miles City, MN, USA.

Wichmann, B.A. \& Hill, I.O., 1982. An efficient and portable pseudo-random number generator. Appl. Stat. 31, 188-190.

Wilson, D.E. \& Willham, R.L., 1986. Within-herd phenotypic, genetic and environmental trend lines for beef cattle breeders. J. Anim. Sci. 63, 1087.

Yamada, Y., Yokouchi, K. \& Nashida, A., 1975. Selection index when genetic gains of individual traits are of primary concern. Jap. J. Genet. 50, 33-41. 